\title{
Variation in general supportive and preventive intensive care management of traumatic brain injury: a survey in 66 neurotrauma centers participating in the Collaborative European NeuroTrauma Effectiveness Research in Traumatic Brain Injury (CENTER-TBI) study
}

Jilske A. Huijben ${ }^{1 *}$, Victor Volovici ${ }^{1,2}$, Maryse C. Cnossen ${ }^{1}$, lain K. Haitsma ${ }^{2}$, Nino Stocchetti ${ }^{3,4}$, Andrew I. R. Maas ${ }^{5}$, David K. Menon ${ }^{6}$, Ari Ercole ${ }^{6}$, Giuseppe Citerio ${ }^{7,8}$, David Nelson ${ }^{9}$, Suzanne Polinder ${ }^{1}$, Ewout W. Steyerberg ${ }^{1,10}$, Hester F. Lingsma', and Mathieu van der Jagt ${ }^{11}$ CENTER-TBI investigators and participants

\begin{abstract}
Background: General supportive and preventive measures in the intensive care management of traumatic brain injury (TBI) aim to prevent or limit secondary brain injury and optimize recovery. The aim of this survey was to assess and quantify variation in perceptions on intensive care unit (ICU) management of patients with TBI in European neurotrauma centers.

Methods: We performed a survey as part of the Collaborative European NeuroTrauma Effectiveness Research in Traumatic Brain Injury (CENTER-TBI) study. We analyzed 23 questions focused on: 1) circulatory and respiratory management; 2) fever control; 3) use of corticosteroids; 4) nutrition and glucose management; and 5) seizure prophylaxis and treatment.

Results: The survey was completed predominantly by intensivists $(n=33,50 \%)$ and neurosurgeons $(n=23,35 \%)$ from 66 centers (97\% response rate).

The most common cerebral perfusion pressure (CPP) target was $>60 \mathrm{mmHg}(n=39,60 \%)$ and/or an individualized target ( $n=25,38 \%)$. To support CPP, crystalloid fluid loading $(n=60,91 \%)$ was generally preferred over albumin $(n=15,23 \%)$, and vasopressors $(n=63,96 \%)$ over inotropes $(n=29,44 \%)$. The most commonly reported target of partial pressure of carbon dioxide in arterial blood $\left(\mathrm{PaCO}_{2}\right)$ was $36-40 \mathrm{mmHg}(4.8-5.3 \mathrm{kPa}$ ) in case of controlled intracranial pressure (ICP) $<20 \mathrm{mmHg}(n=45,69 \%)$ and $\mathrm{PaCO}_{2}$ target of $30-35 \mathrm{mmHg}(4-4.7 \mathrm{kPa})$ in case of raised ICP $(n=40,62 \%)$. Almost all respondents indicated to generally treat fever $(n=65,98 \%)$ with paracetamol $(n=61,92 \%)$ and/or external cooling $(n=49,74 \%)$. Conventional glucose management $(n=43,66 \%)$ was preferred over tight glycemic control $(n=18$, $28 \%)$. More than half of the respondents indicated to aim for full caloric replacement within 7 days $(n=43,66 \%)$ using enteral nutrition ( $n=60,92 \%$ ). Indications for and duration of seizure prophylaxis varied, and levetiracetam was (Continued on next page)
\end{abstract}

\footnotetext{
* Correspondence: j.a.huijben@erasmusmc.nl

${ }^{1}$ Center for Medical Decision Making, Department of Public Health, Erasmus

Medical Center Rotterdam, Rotterdam, the Netherlands

Full list of author information is available at the end of the article
} 
(Continued from previous page)

mostly reported as the agent of choice for both seizure prophylaxis ( $n=32,49 \%)$ and treatment $(n=40,61 \%)$.

Conclusions: Practice preferences vary substantially regarding general supportive and preventive measures in TBI patients at ICUs of European neurotrauma centers. These results provide an opportunity for future comparative effectiveness research, since a more evidence-based uniformity in good practices in general ICU management could have a major impact on TBI outcome.

Keywords: Intensive care unit, Traumatic brain injury, Glucose, Nutrition, Fever, Ventilation, Blood pressure, Seizure, Survey, Europe

\section{Background}

Traumatic brain injury (TBI) is one of the major causes of trauma-related death and hospital admissions in Europe [1]. TBI is recognized as a complex heterogeneous syndrome [2]. The higher vulnerability of this population is reflected by higher mortality rates in patients with TBI compared with non-head injured trauma patients [3]. Therefore, patients with (severe) TBI require specialized neurointensive care (treatment) at an intensive care unit (ICU) [4].

Case fatality rates in severe TBI are high, ranging from $30 \%$ to $40 \%$ in unselected observational series [5]. Furthermore, substantial between-country [1] and betweencenter differences $[3,4,6]$ in overall TBI mortality rates exist which might be partly explained by differences in treatment [7-9].

The key objectives of ICU TBI management are to maintain general physiology and prevent secondary brain injury. A number of brain-specific therapies, such as intracranial pressure (ICP)-guided treatment or, less often, brain-metabolic or cerebral vascular autoregulation-based goals are employed both clinically or as the subject of clinical research [10]. However, general support of the cardiovascular system, respiratory function, and nutritional or metabolic needs must not be overlooked and could also have a significant impact on outcome [11, 12]. Cerebral metabolic control by seizure or fever management may further contribute to better outcomes [2, 13-15]. At present, optimal strategies for general management are only partly established $[16,17]$. This lack of robust evidence may ultimately result in institutional or individual variations in practice that may contribute to variances in outcome.

The aim of this survey study was to assess variation in ICU management perceptions of general supportive and preventive care policies (including, for instance, circulatory and respiratory management) in patients with TBI in European neurotrauma centers.

\section{Methods}

\section{Participating centers}

This study is part of the Collaborative European NeuroTrauma Effectiveness Research in Traumatic Brain Injury (CENTER-TBI) study that collects data on patient characteristics, patient management, and outcomes in 68 centers from 20 countries across Europe and Israel [18]. All these centers were asked to complete a 'Provider Profiling Questionnaire' [19]. The questionnaire items used for this study (treatment at the intensive care) are attached as Additional file 1.

\section{Provider profiling questionnaire}

The provider profiling questionnaire was developed in several stages. First, literature was explored for evidence, including guidelines and available surveys. Second, a pilot study was conducted in 16 participating centers to receive feedback, to determine ambiguity, and to detect unexpected and missing values. Throughout all stages, experts of various disciplines (neurosurgeons, intensivists, neurologists, emergency department physicians, rehabilitation physicians, medical ethicists, health care economists, and epidemiologists) were asked for their advice on the development of the questionnaire. Details on the development, administration, and content of the complete provider profiling questionnaires have been published previously [19].

\section{General supportive and preventive management}

For the purpose of the current study, we focused on 23 questions specifically aimed at general ICU policies (Additional file 1). Specifically, we focused on circulatory and respiratory management, fever control, use of corticosteroids, glucose and nutrition management, and seizure prophylaxis and treatment. Most questions were multiple-choice, except for two questions: the aim for caloric intake in TBI patients and the use of corticosteroids for other conditions. Overall, the general policy of a center rather than the individual treatment preference of the respondent was the premise for completion of the questionnaire. General policy is defined as: 'the way the large majority of patients (> 75\%) with a certain indication would be treated'.

\section{Statistical analysis}

We used descriptive statistics (frequencies and percentages) to present the data. Respondents could indicate how frequently certain management strategies were used (never $0-10 \%$, rarely $10-30 \%$, sometimes $30-70 \%$, 
frequently $70-90 \%$, and always $90-100 \%)$. The combined numbers of respondents that indicated 'frequently' and 'always' were interpreted as representing the general policy of a center, in line with previous reports $[20,21]$. To describe center characteristics in more detail we divided centers into higher (Austria, Belgium, Denmark, Finland, France, Germany, Israel, Italy, the Netherlands, Norway, Spain, Sweden, UK, and Switzerland) versus relatively lower income countries (Bosnia Herzegovina, Hungary, Latvia, Lithuania, Romania, and Serbia), based on a 2007 report by the European Commission [22]. Differences were assessed for statistical significance using the Fisher's exact test without correction for multiple comparisons. We used Statistical Package for Social Sciences (SPSS) version 21 [23] for descriptive analyses.

\section{Results}

\section{Participating centers}

Of the 68 neurotrauma centers participating in this study, 66 (97\%) centers completed the questions on general supportive and preventive ICU management. The questionnaire was predominantly completed by intensivists $(n=33,50 \%)$ and neurosurgeons $(n=23,35 \%)$. Other professionals that assisted in completion of the questionnaire were administrative staff $(n=11,17 \%)$, neurologists $(n=5,8 \%)$, anesthesiologists $(n=5,8 \%)$, and a trauma surgeon $(n=1,2 \%)$.

The majority of centers had an academic affiliation $(n=60,91 \%)$. The majority of centers were designated as level I trauma centers $(n=45,69 \%)$, and a minority as level II $(n=4,6 \%)$, level III $(n=1,2 \%)$, or no designation $(n=15,23 \%)$. More than half of the centers had a dedicated neuroICU (defined as an ICU that is equipped to treat patients with neurological or neurosurgical injury) available ( $n=39,59 \%)$. The majority of centers adopted a 'closed' ICU organization (the intensivist is primarily responsible for the delivery of care for patients at the ICU) $(n=43,65 \%)$, followed by a 'mixed' ICU organization (the admitting physician, e.g., neurosurgeon, is primarily responsible but the care is provided by a intensivist) $(n=20,30 \%)$, and a minority adopted an 'open' ICU organization (the admitting physician is primarily responsible for care at the $\mathrm{ICU})(n=3,5 \%)$. Centers indicated to treat a median of 92 (interquartile range 52-160) patients with TBI at their ICU annually. Twenty-eight centers (42\%) reported to adhere to the 2007 Brain Trauma Foundation (BTF) guidelines for the management of patients with TBI at their ICU, and 21 centers (32\%) reported having institutional guidelines that were based on BTF guidelines. The center characteristics and definitions are described in more detail in a previous publication [19].

\section{Circulatory and respiratory management}

As part of circulatory management, the most frequently mentioned cerebral perfusion pressure (CPP) targets were $>60 \mathrm{mmHg}(n=39,60 \%)$ and/or "individualized" $(n=25,38 \%)$. Most centers used crystalloids $(n=60$, 91\%) and/or vasopressors $(n=63,96 \%)$ for CPP support; inotropes $(n=29,44 \%)$ were less frequently, but still regularly, employed. Fifteen centers (23\%) reported to use albumin-containing solutions for volume expansion (Additional file 2: Table S1).

In mechanically ventilated patients with $\mathrm{TBI}$, initial partial pressure of oxygen in arterial blood $\left(\mathrm{PaO}_{2}\right)$ goals of $>75 \mathrm{mmHg}(10 \mathrm{kPa})(n=29,45 \%)$ and $>97.5$ $\mathrm{mmHg}(13 \mathrm{kPa})(n=29,45 \%)$ were most commonly cited as a treatment preference, with an initial arterial oxygen saturation goal of $>95 \%(n=56,86 \%)$. In the absence of raised ICP, most centers indicated a partial pressure of carbon dioxide in arterial blood $\left(\mathrm{PaCO}_{2}\right)$ goal of $36-40 \mathrm{mmHg}(4.8-5.3 \mathrm{kPa})(n=45,69 \%)$. In the presence of raised ICP this shifted towards a lower $\mathrm{PaCO}_{2}$ goal of $30-35 \mathrm{mmHg}(4.0-4.7 \mathrm{kPa})(n=40$, 62\%) (Fig. 1). The timing of tracheostomy in patients with limited or slow neurological recovery varied substantially from within 1 week $(n=13,20 \%)$ to between 1 and 2 weeks $(n=36,55 \%)$ and more than 2 weeks $(n=16,25 \%)$ (Additional file 2: Table S1).

Relatively lower income countries more frequently adopted lower oxygen saturation goals $(>90 \%)$ compared with saturation targets $>95 \%$ which were favored by higher income countries $(n=3 / 11,27 \%$, versus $n=2 / 55$, $4 \% ; p=0.037$ ) (Additional file 3: Table S6).

\section{Fever control}

In patients with TBI, the majority of centers indicated that they routinely treat fever $(n=65,98 \%)$. One center (2\%) reported they would only treat fever "sometimes". The preferred treatments were paracetamol $(n=61$, $92 \%)$ and/or external cooling $(n=49,74 \%)$. In contrast, nonsteroidal anti-inflammatory drugs (NSAIDs) were less commonly used $(n=29,44 \%)$. Intravascular cooling was also rarely used ( $n=3,5 \%)$ (Fig. 2) (Additional file 2: Table S2).

Relatively lower income countries significantly indicated the use of NSAIDs more often than higher income countries $(n=11 / 11,100 \%$, versus $n=18 / 55$, $33 \% ; p=0.000)$. Centers in higher income countries indicated the use of paracetamol significantly more frequently compared with relatively lower income countries $(n=53 / 55,96 \%$, versus $n=8 / 11,73 \% ; p=$ 0.029). Intravascular cooling was more frequently applied in the lower income group, although this difference did not reach statistical significance (Additional file 3: Table S7). 

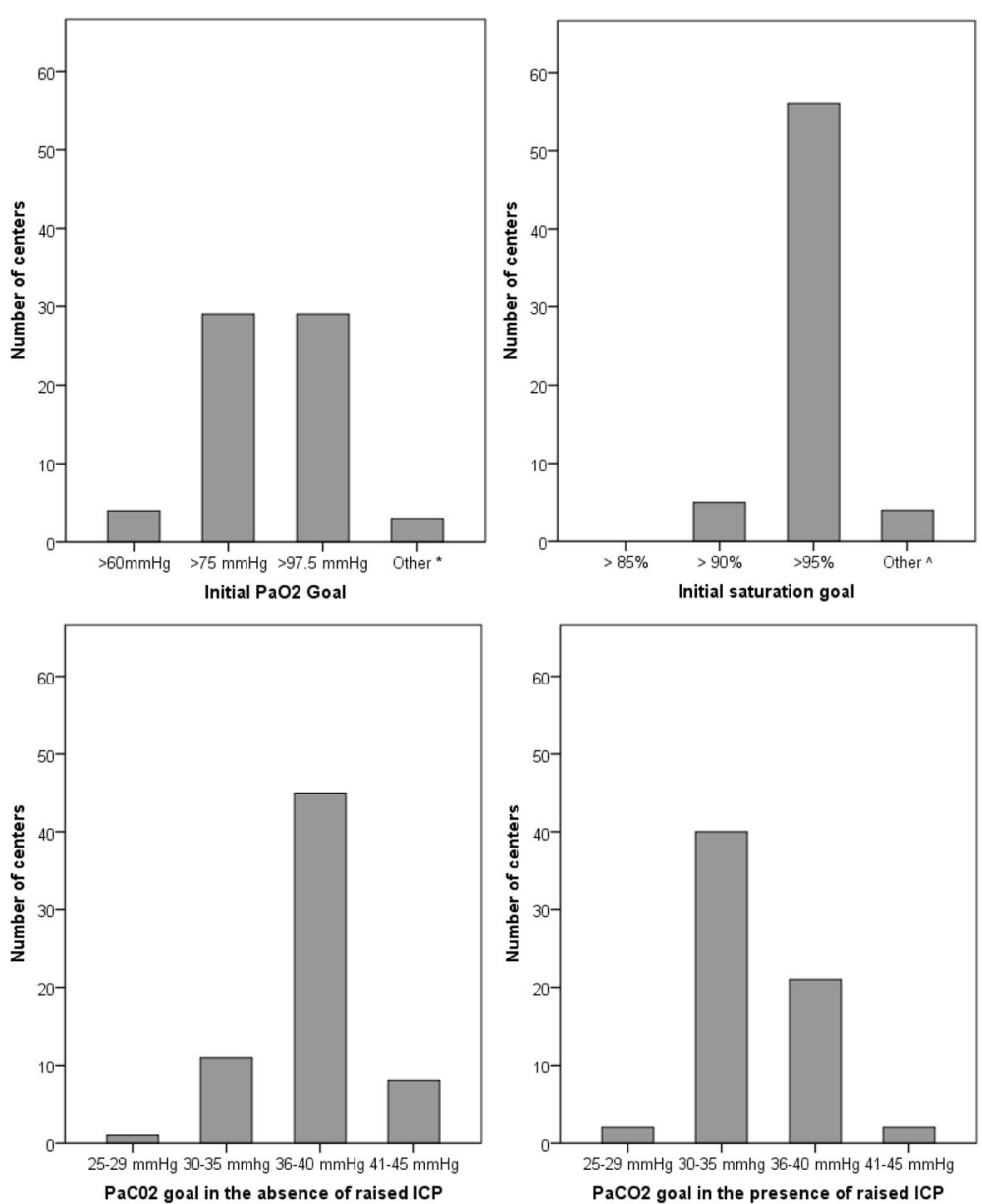

Fig. 1 Mechanical ventilation thresholds with corresponding answer frequencies; $25-29 \mathrm{mmHg} \approx 3.3-3.0 \mathrm{kPa}, 30-35 \mathrm{mmHg} \approx 4-4.7 \mathrm{kPa}$, 36-40 $\mathrm{mmHg} \approx 4.8-5.3 \mathrm{kPa}, 41-45 \mathrm{mmHg} \approx 5.5-6 \mathrm{kPa}, 60 \mathrm{mmHg}=8 \mathrm{kPa}, 75 \mathrm{mmHg}=10 \mathrm{kPa}, 100 \mathrm{mmHg}=13 \mathrm{kPa}$. ${ }^{*}$ No specific goal $(n=1),>90$ $\mathrm{mmHg}(n=2){ }^{\wedge}>96 \%(n=2),>97 \%(n=1), 92-94 \%(n=1)$. PaCO2 partial pressure of carbon dioxide in arterial blood, PaO2 partial pressure of oxygen in arterial blood

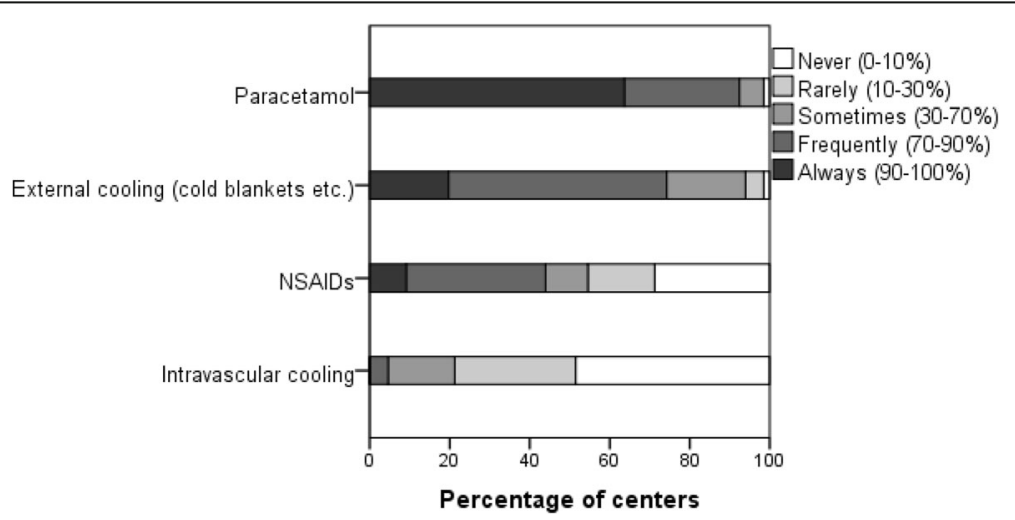

Fig. 2 Type of fever treatment and corresponding percentage of centers that indicated they use this type of fever treatment never (in 0-10\% of cases), rarely (in $10-30 \%$ of cases), sometimes (in 30-70\% of cases), frequently (in $70-90 \%$ of cases), or always (in $90-100 \%$ of cases). NSAID nonsteroidal anti-inflammatory drug 


\section{Use of corticosteroids}

Corticosteroids were infrequently used for the primary management of brain injury, although a few respondents indicated that they used them "rarely" $(n=5,8 \%)$, "sometimes" $(n=2,3 \%)$, or "frequently" $(n=1,2 \%)$. However, corticosteroids were specifically used for vasopressorresistant hypotension $(n=21,58 \%)$ and, to a lesser extent, sepsis $(n=8,22 \%)$ (Additional file 2: Table S3).

Primary use of corticosteroids was significantly more frequently reported by lower income countries compared with higher income countries $(n=4 / 11,36 \%$, versus $n=4 / 55,7 \% ; p=0.023$ ) (Additional file 3: Table S7).

\section{Glucose and nutrition management}

The majority of centers stated that their glucose management was protocolized $(n=50,77 \%)$. Most centers reported the correction of hyperglycemia as a primary aim $(n=43,66 \%)$ while a smaller number implemented tight glycemic control $(n=18,28 \%)$ (Additional file 2: Table S4).

Most respondents aimed for full caloric replacement within 7 days post-injury $(n=43,66 \%)$. An open question on the goals for caloric intake showed a high variety in reported strategies as well as metrics used (kcal/day, $\mathrm{kcal} / \mathrm{kg} /$ day, and percentages). The enteral route was preferred $(n=60,92 \%)$. The timing of parenteral nutrition was highly variable: centers were equally distributed between "as soon as possible" ( $n=13,20 \%)$, "within $24 \mathrm{~h}$ post-injury" ( $n=13,20 \%)$, "within $72 \mathrm{~h}$ post-injury" ( $n=$ $10,15 \%)$, "within 7 days post-injury" $(n=17,26 \%)$, and "we do not have rules/guidelines for this" $(n=12,19 \%)$ (Additional file 2: Table S4).
Relatively lower income countries reported using the parenteral route significantly more frequently compared with higher income countries $(n=4 / 11,36 \%$, versus $n=$ $1 / 55,2 \%, p=0.002$ ) (Additional file 3: Table S7).

\section{Seizure prophylaxis and treatment}

There was little consensus regarding the use of prophylactic antiepileptic drugs (for all indications). Most centers reported to use levetiracetam as the drug of choice for both seizure prophylaxis and treatment $(n=32,49 \%$, and $n=40,61 \%)$, followed by phenytoin $(n=20,31 \%$, and $n=32,48 \%$ ) (Fig. 3). In general, both the reported duration of antiseizure prophylaxis and the criteria for initiation of antiepileptic treatment varied considerably (Additional file 2: Table S5).

The choice of agent varied with income, with levetiracetam being less commonly used for both seizure prophylaxis $(n=0 / 11$ versus $n=32 / 55,59 \% ; p=0.000)$ and treatment $(n=1 / 11,9 \%$, versus $n=39 / 55,71 \% ; p=$ $0.000)$ in the lower income group versus higher income countries, respectively. Instead, lower income countries seemed to favor valproate or phenytoin compared with higher income countries $(n=7 / 11,64 \%$, versus $n=14$ / $55,26 \% ; p=0.029$ ) (Additional file 3: Table S7).

\section{Discussion}

In this survey, we found varying degrees of consensus between European neurotrauma centers with respect to general supportive and preventive ICU management in patients with TBI. Most variation was found in initial $\mathrm{PaO}_{2}$ goals for mechanically ventilated patients, CPP

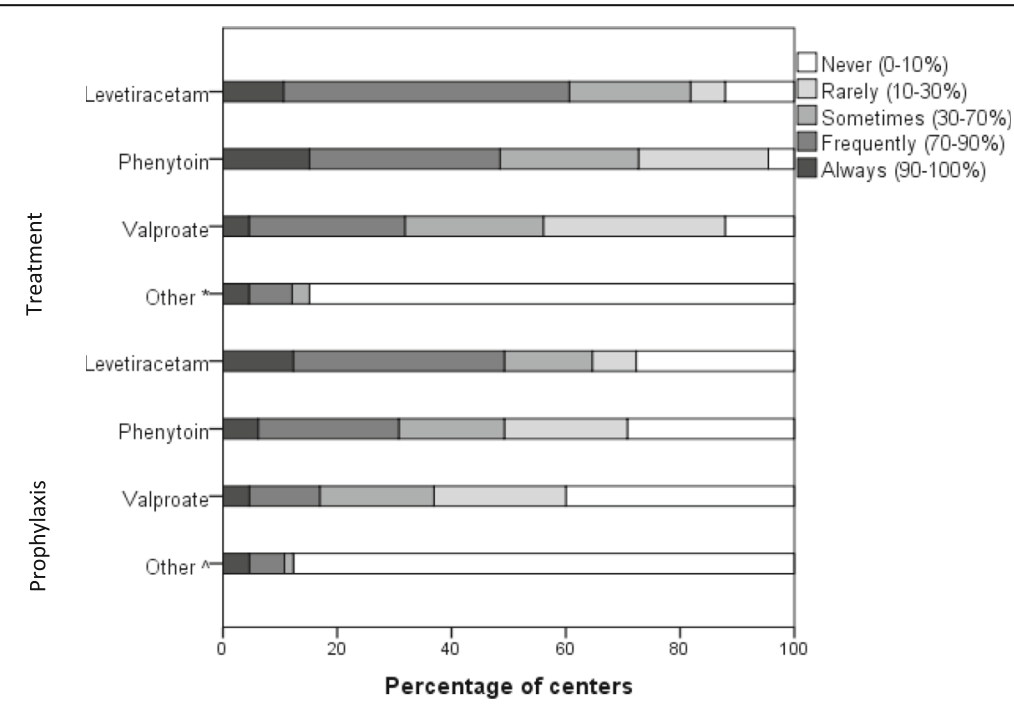

Fig. 3 Agents for seizure prophylaxis and treatment with corresponding percentage of centers that indicated that they never (in 0-10\% of cases), rarely (in 10-30\% of cases), sometimes (in 30-70\% of cases), frequently (in 70-90\% of cases), or always (in 90-100\% of cases) use the agent. ${ }^{*}$ Carbamazepine/phenobarbital, phenobarbital, benzodiazepines, no prophylaxis used in our hospital, carbamazepine $(n=3)$. ${ }^{\wedge}$ Phenobarbital, benzodiazepines, carbamazepine $(n=4)$, midazolam/diazepam, lorazepam 
targets, the timing of tracheostomy in unconscious patients, nutritional targets, and seizure prophylaxis and treatment.

Large between-center variation was found in topics that are not addressed in the recommendations of the BTF guidelines (Additional file 4), suggesting the role of guidelines in reducing variances in clinical practice. International guidelines (BTF guidelines and guidelines of the American College of Surgeons) do recommend the use of normalized thresholds (e.g., normoglycemia, normocapnia, and normothermia) in patients with TBI, although this is not based on high-level evidence [16, 17]. Indeed, randomized controlled trials (RCTs) on these topics are too limited in number to lead to high-level evidence [10]. Considering CPP targets, the BTF guidelines are unclear whether to use an optimum threshold of $>60$ or $>70 \mathrm{mmHg}$ (and a range of $50-70 \mathrm{mmHg}$ in the previous BTF guidelines [24]). Despite this ambiguity, a majority of respondents (60\%) preferred a target CPP of > $60 \mathrm{mmHg}$. In addition, the current BTF guidelines added that the CPP target might depend on the individual cerebral autoregulatory status, reflected by $38 \%$ of respondents who indicated to use an individualized target CPP. The uniformity in reported CPP targets between income groups also suggests that these concepts are widespread. It may be that the willingness to individualize CPP in patients with TBI reflects the growing trend for use of precision medicine [25], where therapies and therapy targets are individualized to patient need, rather than used on a "one size fits all" basis.

Marked variation was also found on topics where consensus was expected based on high-level evidence from RCTs or the recommendations in the BTF guidelines. The use of steroids for the primary management of TBI was reported by $13 \%$ of the respondents (one respondent reported frequent use), but is against the advice of the BTF guidelines and contradicts the prevailing evidence from the CRASH study [26, 27]. However, use in the majority of centers was for vasopressor dependence and/ or sepsis, a use in keeping with current guidelines for the management of sepsis [28]. The use of albumin was reported by $23 \%$ of the respondents, while the SAFE study showed that albumin was associated with higher mortality rates in patients with TBI [29]. It is difficult to interpret the continued use of albumin for volume expansion as a lack of knowledge of the evidence, since worse outcomes in the albumin-treated arm in SAFETBI may have been the consequence of a hypotonic carrier causing elevated ICP [30], and well-informed clinicians may have used albumin that was isotonic or corrected any accompanying hyponatremia. Finally, the use of tight glycemic control was reported by $28 \%$ of respondents, while the NICE-SUGAR and CGAO-REA studies recommend using moderate instead of tight glucose control in patients with TBI $[31,32]$.
On the other hand, we found consensus where variation was expected; a high number of centers indicated they use antipyretic agents for the treatment of fever when there is no consensus on the optimal choice of agent and when their potentially deleterious side-effect of CPP lowering is well known [33]. This suggests a strong aversion amongst treating clinicians to allow pyrexia in patients with TBI. The choice of NSAIDs, despite their well-known potentially harmful systemic side-effect profile, as antipyretics in many centers probably also reflects this, although a continuous intravenous infusion instead of intermittent NSAID dosing might improve fever control (with relatively higher CPP) in neurocritical care [34]. In addition, respondents indicated employing below-normal $\mathrm{PaCO}_{2}$ goals $(30-35 \mathrm{mmHg}$ ) in the presence of raised ICP in mechanically ventilated TBI patients. This was unexpected given the BTF recommendation to avoid prolonged hyperventilation. Furthermore, even patients in whom intracranial hypertension was not a concern were ventilated to normal carbon dioxide tensions showing a reluctance to use permissive ventilatory strategies that have been shown to be effective in reducing mortality in acute respiratory distress syndrome (ARDS) patients [35].

Our results further suggest that respondents use TBIspecific strategies instead of general strategies (as used in the general critically ill patients) in the ICU. For example, respondents indicated they frequently or always treat fever since hyperthermia is associated with worse outcomes in TBI [14, 33], whereas fever is often considered beneficial to some extent in critically ill patients with infections [36].

We found some differences between relatively lower versus higher income countries. It was striking that levetiracetam was significantly more frequently reported by higher income countries as an agent of choice for seizure prophylaxis and treatment, while valproate and phenytoin were reported more frequently by lower income countries, although high-level evidence in the literature on the agent of choice is lacking [37]. However, there were no clear structural differences in management overall, and this could not therefore be considered an explanation for the treatment variation. Indeed, some high-cost interventions, such as intravascular cooling and parenteral nutrition, were more commonly used in the lower income countries, suggesting that choices of treatment options are not solely based on cost considerations, but also reflect local clinical culture in different institutions.

Our study has several strengths. To our knowledge, this is the first survey that provides an overview of multiple components of general supportive or preventive ICU management in patients with TBI. The survey was developed in several stages with involvement of clinical 
experts of various disciplines and the response rate of the survey was high (97\%). However, this study also has limitations, as the centers participating in the CENTERTBI study may still be a biased selection of European centers with a specialist interest in the topic, or a large engagement in research, or more expertise overall. In a small number of centers, the questionnaire was completed by administrative staff (with no clinical expertise). However, presumably this was in close collaboration with a clinician considering the high number of clinicians that completed the survey, and clinical involvement was encouraged throughout the survey. Other limitations are inherent to surveys in that the results are self-reported and are not confirmed by independent observations in daily practice and, therefore, represent what the respondents 'believe' is clinical practice and this may not, in fact, reflect reality. Another limitation is that the survey questions represent generalizations and do not include patient factors (such as demographics, laboratory results, or imaging), or very specific circumstances, while in clinical practice these details influence clinicians' judgement. In line with this, we did not specify time frames (for ventilation goals) and laboratory values (for tight glucose control). Also, we asked about general patients with TBI in the survey and did not specify adult or pediatric TBI.

Overall, the practice variation (and consensus) in general ICU management we found might be explained by a lack of evidence (or incomplete implementation of evidence), by the use of individualized approaches, or by a tension between general and TBI-specific strategies. We presume that increased and more evidence-based uniformity in good practices in general ICU management might improve outcome in TBI. In fact, general ICU management is part of daily routine (e.g., temperature measurements, laboratory results, and mechanical ventilation) and deviations are generally easily detected and corrected. It is noteworthy that non-neurological complications are frequent; in one report on TBI patients these were more frequent (around 22\%) than neurological complications (around 3\%) [29]. Our survey showed that future research on individualized management is needed; a high number of respondents reported individualized practices which implies a trend towards precision medicine. In addition, the existence of practice variation in general ICU management provides direction to comparative effectiveness research (CER) analyses or RCTs. As RCTs in the field of TBI have been disappointing [10], CER might be a promising approach to enhance future knowledge on the effectiveness of general ICU management, and understanding what process variances occur, as we have attempted to do, is a critical starting point. Hence, in the CENTER-TBI study we will evaluate the effect of different ICU management practices on TBI outcome (after case-mix correction); for example, the difference in patient outcome between the 13 centers that plan tracheostomy within 1 week, the 36 centers that time tracheostomy between 1 and 2 weeks, and the 16 centers that delay tracheostomy longer than 2 weeks.

\section{Conclusions}

This study shows that general supportive and preventive ICU management policies in TBI vary between European neurotrauma centers. These findings stress the need for continued knowledge transfer of existing evidence, further research on optimized individualized management (precision medicine) and, as we propose, comparative effectiveness research.

\section{Additional files}

Additional file 1: Survey questions: survey questions of the 'Provider Profiling Questionnaire' used in the study (treatment in the intensive care unit). (DOCX $23 \mathrm{~kb}$ )

Additional file 2: Overview of all results: circulatory and respiratory management (Table S1), fever control (Table S2), use of corticosteroids (Table S3), glucose and nutrition management (Table S4), seizure prophylaxis and treatment (Table S5). (DOCX 26 kb)

Additional file 3: Variation between higher and lower income countries: variation in thresholds used for circulatory and respiratory management (Table S6) and general treatments in the ICU (Table S7). (DOCX $22 \mathrm{~kb}$ )

Additional file 4: Comparison with the Brain Trauma foundation recommendations: items of the questionnaire with corresponding recommendations in the Brain Trauma Foundation guidelines for the Management of Severe Traumatic Brain Injury (4th edition). (DOCX 17 kb)

Additional file 5: CENTER-TBI investigators and participants participating in the CENTER-TBI study and their corresponding affiliations. (DOCX 33 kb)

\section{Abbreviations \\ BTF: Brain trauma foundation; CENTER-TBI: Collaborative european neurotrauma effectiveness research in traumatic brain injury; CER: Comparative effectiveness research; CPP: Cerebral perfusion pressure; ICP: Intracranial pressure; ICU: Intensive care unit; NSAID: Nonsteroidal anti- inflammatory drug; $\mathrm{PaCO}_{2}$ : Partial pressure of carbon dioxide in arterial blood; $\mathrm{PaO}_{2}$ : Partial pressure of oxygen in arterial blood; $\mathrm{RCT}$ : Randomized controlled trial; TBI: Traumatic brain injury}

\section{Acknowledgements}

The authors would like to thank all clinical and research staff at the CENTER-TBI sites for completing the provider profiling questionnaires. The CENTER-TBI investigators and participants are listed in Additional file 5.

\section{Funding}

European Commission FP7 Framework Program 602150. Data used in the preparation of this manuscript were obtained in the context of CENTER-TBI, a large collaborative project with the support of the European Commission 7th Framework program (602150). The funder had no role in the design of the study, the collection, analysis, and interpretation of data, or in writing the manuscript.

\section{Availability of data and materials}

There are legal constraints that prohibit us from making the data publicly available. Since there are only a limited number of centers per country included in this study (for two countries only one center), data will be identifiable. Readers may contact Dr. Hester F. Lingsma (h.lingsma@erasmusmc.nl) for reasonable requests for the data. 


\section{Authors' contributions}

JAH analyzed the data and drafted the manuscript, the supplementary tables and the figures. W and MvdJ gave feedback on the manuscript and MvdJ supervised the project. All coauthors were involved in the design of the survey and the distribution of the survey. All coauthors gave feedback on (and approved) the final version of the manuscript.

\section{Ethics approval and consent to participate}

Not applicable since no patients participated, and the centers have given consent by completing the questionnaire.

\section{Consent for publication}

Not applicable.

\section{Competing interests}

The authors declare that they have no competing interests.

\section{Publisher's Note}

Springer Nature remains neutral with regard to jurisdictional claims in published maps and institutional affiliations.

\section{Author details}

${ }^{1}$ Center for Medical Decision Making, Department of Public Health, Erasmus Medical Center Rotterdam, Rotterdam, the Netherlands. ${ }^{2}$ Department of Neurosurgery, Office H-703, Erasmus MC Stroke Center and Brain Tumor Center, Erasmus Medical Center Rotterdam, Rotterdam, The Netherlands. ${ }^{3}$ Department of Pathophysiology and Transplants, University of Milan, Milan, Italy. ${ }^{4}$ Fondazione IRCCS Ca' Granda, Ospedale Maggiore Policlinico, Department of Anesthesia and Critical Care, Neuroscience Intensive Care Unit, Milan, Italy. ${ }^{5}$ Department of Neurosurgery, Antwerp University Hospital and University of Antwerp, Edegem, Belgium. ${ }^{6}$ Division of Anaesthesia, University of Cambridge, Addenbrooke's Hospital, Cambridge, UK. ${ }^{7}$ School of Medicine and Surgery, University of Milan-Bicocca, Milan, Italy. ${ }^{8}$ Neurointensive Care, San Gerardo Hospital, ASST-Monza, Monza, Italy. ${ }^{9}$ Section for Perioperative Medicine and Intensive Care, Department of Physiology and Pharmacology, Karolinska Institutet, Stockholm, Sweden. ${ }^{10}$ Department of Medical Statistics and Bioinformatics, Leiden University Medical Center, Leiden, the Netherlands. "1Department of Intensive Care and Erasmus MC Stroke Center, Erasmus Medical Center, Rotterdam, the Netherlands.

\section{Received: 31 October 2017 Accepted: 19 February 2018} Published online: 13 April 2018

\section{References}

1. Majdan MDP. Epidemiology of traumatic brain injuries in Europe: a crosssectional analysis. Lancet Public Health. 2016;1:e76-83.

2. Stocchetti N, Carbonara M, Citerio G, Ercole A, Skrifvars MB, Smielewski $P$, Zoerle T, Menon DK. Severe traumatic brain injury: targeted management in the intensive care unit. Lancet Neurol. 2017;16(6):452-64.

3. Patel HC, Bouamra O, Woodford M, King AT, Yates DW, Lecky FE, Trauma A, Research N. Trends in head injury outcome from 1989 to 2003 and the effect of neurosurgical care: an observational study. Lancet. 2005: 366(9496):1538-44.

4. Moore L, Evans D, Hameed SM, Yanchar NL, Stelfox HT, Simons R, Kortbeek J, Bourgeois G, Clement J, Lauzier F, et al. Mortality in Canadian trauma systems: a multicenter cohort study. Ann Surg. 2017:265(1):212-7.

5. Rosenfeld JV, Maas Al, Bragge P, Morganti-Kossmann MC, Manley GT, Gruen RL. Early management of severe traumatic brain injury. Lancet. 2012; 380(9847):1088-98

6. Lingsma HF, Roozenbeek B, Li B, Lu J, Weir J, Butcher I, Marmarou A, Murray $\mathrm{GD}$, Maas Al, Steyerberg EW. Large between-center differences in outcome after moderate and severe traumatic brain injury in the international mission on prognosis and clinical trial design in traumatic brain injury (IMPACT) study. Neurosurgery. 2011;68(3):601-7. discussion 607-8

7. Cnossen MC, Polinder S, Andriessen TM, van der Naalt J, Haitsma I, Horn J, Franschman G, Vos PE, Steyerberg EW, Lingsma H. Causes and consequences of treatment variation in moderate and severe traumatic brain injury: a multicenter study. Crit Care Med. 2017;45(4):660-9.
8. Bulger EM, Nathens AB, Rivara FP, Moore M, MacKenzie EJ, Jurkovich GJ, Brain TF. Management of severe head injury: institutional variations in care and effect on outcome. Crit Care Med. 2002;30(8):1870-6.

9. Alali AS, Fowler RA, Mainprize TG, Scales DC, Kiss A, de Mestral C, Ray JG, Nathens AB. Intracranial pressure monitoring in severe traumatic brain injury: results from the American College of Surgeons Trauma Quality Improvement Program. J Neurotrauma. 2013;30(20):1737-46.

10. Bragge P, Synnot A, Maas Al, Menon DK, Cooper DJ, Rosenfeld JV, Gruen RL. A state-of-the-science overview of randomized controlled trials evaluating acute management of moderate-to-severe traumatic brain injury. J Neurotrauma. 2016:33(16):1461-78.

11. Mascia L, Sakr Y, Pasero D, Payen D, Reinhart K, Vincent JL, Sepsis Occurrence in Acutely III Patients (SOAP) Investigators. Extracranial complications in patients with acute brain injury: a post-hoc analysis of the SOAP study. Intensive Care Med. 2008:34(4):720-7.

12. Costello LA, Lithander FE, Gruen RL, Williams LT. Nutrition therapy in the optimisation of health outcomes in adult patients with moderate to severe traumatic brain injury: findings from a scoping review. Injury. 2014:45(12):1834-41.

13. Stocchetti N, Taccone FS, Citerio G, Pepe PE, Le Roux PD, Oddo M, Polderman $\mathrm{KH}$, Stevens RD, Barsan W, Maas Al, et al. Neuroprotection in acute brain injury: an up-to-date review. Crit Care. 2015;19:186.

14. Bonds BW, Hu P, Li Y, Yang S, Colton K, Gonchigar A, Cheriyan J, Grissom T, Fang R, Stein DM. Predictive value of hyperthermia and intracranial hypertension on neurological outcomes in patients with severe traumatic brain injury. Brain Inj. 2015;29(13-14):1642-7.

15. Majidi S, Makke Y, Ewida A, Sianati B, Qureshi Al, Koubeissi MZ. Prevalence and risk factors for early seizure in patients with traumatic brain injury: analysis from National Trauma Data Bank. Neurocrit Care. 2017;27(1):90-5.

16. Carney N, Totten AM, O'Reilly C, Ullman JS, Hawryluk GW, Bell MJ, Bratton SL, Chesnut R, Harris OA, Kissoon N, et al. Guidelines for the management of severe traumatic brain injury, fourth edition. Neurosurgery. 2017:80(1):6-15.

17. American College of Surgeons, Trauma Quality Improvement Program guideline: Best Practices in the Management of Traumatic Brain Injury. https://www.facs.org/quality-programs/trauma/tqip/best-practice.

18. Maas Al, Menon DK, Steyerberg EW, Citerio G, Lecky F, Manley GT, Hill S, Legrand V, Sorgner A, Participants C-T, et al. Collaborative European NeuroTrauma Effectiveness Research in Traumatic Brain Injury (CENTER-TBI): a prospective longitudinal observational study. Neurosurgery. 2015;76(1):67-80.

19. Cnossen MC, Polinder S, Lingsma HF, Maas Al, Menon D, Steyerberg EW, CENTER-TBI Investigators and Participants. Variation in structure and process of care in traumatic brain injury: provider profiles of European neurotrauma centers participating in the CENTER-TBI study. PLoS One. 2016;11(8):e0161367.

20. Hesdorffer DC, Ghajar J. Marked improvement in adherence to traumatic brain injury guidelines in United States trauma centers. J Trauma. 2007;63(4):841-7. discussion 847-8

21. Cnossen MC, Huijben JA, van der Jagt M, Volovici $V$, van Essen $T$, Polinder $S$ Nelson D, Ercole A, Stocchetti N, Citerio G, et al. Variation in monitoring and treatment policies for intracranial hypertension in traumatic brain injury: a survey in 66 neurotrauma centers participating in the CENTER-TBI study. Crit Care. 2017:21(1):233.

22. European Commission. Remuneration of researchers in the public and private sectors. Brussels: European Communities; 2007.

23. Corp IBM. IBM SPSS Statistics for Windows (or Macintosh), Version 21.0. Armonk: IBM Corp.; 2012

24. Brain Trauma Foundation, American Association of Neurological Surgeons, Congress of Neurological Surgeons. Guidelines for the management of severe traumatic brain injury. J Neurotrauma. 2007;24(Suppl 1):S1-106.

25. Maas AIR, Menon DK, Adelson PD, Andelic N, Bell MJ, Belli A, Bragge P, Brazinova A, Buki A, Chesnut RM, et al. Traumatic brain injury: integrated approaches to improve prevention, clinical care, and research. Lancet Neurol. 2017:16(12):987-1048

26. Roberts I, Yates D, Sandercock P, Farrell B, Wasserberg J, Lomas G, Cottingham R, Svoboda P, Brayley N, Mazairac G, et al. Effect of intravenous corticosteroids on death within 14 days in 10008 adults with clinically significant head injury (MRC CRASH trial): randomised placebo-controlled trial. Lancet. 2004;364(9442):1321-8.

27. Edwards $P$, Arango M, Balica L, Cottingham R, El-Sayed H, Farrell B, Fernandes J, Gogichaisvili T, Golden N, Hartzenberg B, et al. Final results of MRC CRASH, a randomised placebo-controlled trial of intravenous corticosteroid in adults with head injury-outcomes at 6 months. Lancet. 2005;365(9475):1957-9. 
28. Rhodes A, Evans LE, Alhazzani W, Levy MM, Antonelli M, Ferrer R, Kumar A, Sevransky JE, Sprung CL, Nunnally ME, et al. Surviving Sepsis Campaign: international guidelines for management of sepsis and septic shock: 2016. Crit Care Med. 2017:45(3):486-552.

29. SAFE Study Investigators, Australian and New Zealand Intensive Care Society Clinical Trials Group, Australian Red Cross Blood Service, George Institute for International Health, Myburgh J, Cooper DJ, Finfer S, Bellomo R, Norton $\mathrm{R}$, et al. Saline or albumin for fluid resuscitation in patients with traumatic brain injury. N Engl J Med. 2007;357(9):874-84.

30. Cooper DJ, Myburgh J, Heritier S, Finfer S, Bellomo R, Billot L, Murray L, Vallance S, SAFE-TBI Investigators, Australian and New Zealand Intensive Care Society Clinical Trials Group. Albumin resuscitation for traumatic brain injury: is intracranial hypertension the cause of increased mortality? J Neurotrauma. 2013;30(7):512-8.

31. NICE-SUGAR Study Investigators for the Australian and New Zealand Intensive Care Society Clinical Trials Group and the Canadian Critical Care Trials Group, Finfer S, Chittock D, Li Y, Foster D, Dhingra V, Bellomo R, Cook $D$, et al. Intensive versus conventional glucose control in critically ill patients with traumatic brain injury: long-term follow-up of a subgroup of patients from the NICE-SUGAR study. Intensive Care Med. 2015;41(6):1037-47.

32. Cinotti R, Ichai C, Orban JC, Kalfon P, Feuillet F, Roquilly A, Riou B, Blanloeil $Y$, Asehnoune K, Rozec B. Effects of tight computerized glucose control on neurological outcome in severely brain injured patients: a multicenter subgroup analysis of the randomized-controlled open-label CGAO-REA study. Crit Care. 2014;18(5):498.

33. Stocchetti N, Rossi S, Zanier ER, Colombo A, Beretta L, Citerio G. Pyrexia in head-injured patients admitted to intensive care. Intensive Care Med. 2002;28(11):1555-62.

34. Cormio M, Citerio G. Continuous low dose diclofenac sodium infusion to control fever in neurosurgical critical care. Neurocrit Care. 2007;6(2):82-9.

35. Acute Respiratory Distress Syndrome Network, Brower RG, Matthay MA, Morris A, Schoenfeld D, Thompson BT, Wheeler A. Ventilation with lower tidal volumes as compared with traditional tidal volumes for acute lung injury and the acute respiratory distress syndrome. N Engl J Med. 2000;342(18):1301-8.

36. Chiumello D, Gotti M, Vergani G. Paracetamol in fever in critically ill patients - an update. J Crit Care. 2017;38:245-52.

37. Khan NR, VanLandingham MA, Fierst TM, Hymel C, Hoes K, Evans LT, Mayer R, Barker F, Klimo P Jr. Should levetiracetam or phenytoin be used for posttraumatic seizure prophylaxis? A systematic review of the literature and meta-analysis. Neurosurgery. 2016;79(6):775-82.

\section{Submit your next manuscript to BioMed Central and we will help you at every step:}

- We accept pre-submission inquiries

- Our selector tool helps you to find the most relevant journal

- We provide round the clock customer support

- Convenient online submission

- Thorough peer review

- Inclusion in PubMed and all major indexing services

- Maximum visibility for your research

Submit your manuscript at www.biomedcentral.com/submit 